\title{
Evaluating the efficiency of divestiture policy in promoting competitiveness using an analytical method and agent-based computational economics
}

\author{
Morteza Rahimiyan, Habib Rajabi Mashhadi* \\ Department of Electrical Engineering, Faculty of Engineering, Ferdowsi University of Mashhad, Mashhad, Iran
}

\section{A R T I C L E I N F O}

Article history:

Received 26 May 2009

Accepted 13 November 2009

Available online 22 December 2009

Keywords:

Electricity market

Divestiture policy

Agent-based computational economics

\begin{abstract}
A B S T R A C T
Choosing a desired policy for divestiture of dominant firms' generation assets has been a challenging task and open question for regulatory authority. To deal with this problem, in this paper, an analytical method and agent-based computational economics (ACE) approach are used for ex-ante analysis of divestiture policy in reducing market power. The analytical method is applied to solve a designed concentration boundary problem, even for situations where the cost data of generators are unknown. The concentration boundary problem is the problem of minimizing or maximizing market concentration subject to operation constraints of the electricity market. It is proved here that the market concentration corresponding to operation condition is certainly viable in an interval calculated by the analytical method. For situations where the cost function of generators is available, the ACE is used to model the electricity market. In ACE, each power producer's profit-maximization problem is solved by the computational approach of Q-learning. The power producer using the Q-learning method learns from past experiences to implicitly identify the market power, and find desired response in competing with the rivals. Both methods are applied in a multi-area power system and effects of different divestiture policies on market behavior are analyzed.
\end{abstract}

(c) 2009 Elsevier Ltd. All rights reserved.

\section{Introduction}

Since liberalization of electricity markets around the world, the market power has been still a major problem that demotes competitiveness and reduces market efficiency. There is evidence in the European and US electricity markets that the market power is not the only reason but one of the main reasons for increasing electricity prices (Matthes et al., 2005; Müsgens, 2004; Newbery, 2002; Borenstein et al., 2002). Indeed, peculiarities of electricity market related to nature of electricity goods and market structure have made this economic system more vulnerable to the market power abuse.

Studies of restructured markets in England and Wales, Germany, Italy, Belgium, Spain, and Texas and Colorado have shown that the highly concentrated structure of these markets has been a key factor in experiencing uncompetitive behaviors (Domanico, 2007; Bower et al., 2001; London Economics, 2004; Wolak, 2005; Zarnikau, 2005; Sweester, 1999). If a power supplier owns significant generation assets and market share, he has more incentive to raise price by reducing output of generating units or increasing bidding prices. This case can be seen especially in

\footnotetext{
* Corresponding author. Tel./fax: +98 5118763302.

E-mail addresses: morteza_rahimiyan@yahoo.com (M. Rahimiyan), h_mashhadi@um.ac.ir (H. Rajabi Mashhadi).
}

newly established competitive markets where monopolistic markets are opened up for the competition. In this condition, competition policies categorized in rule-based and structural remedies are generally used to preclude the market power and to increase the degree of competitiveness. Divestiture is a kind of structural remedy that changes the market structure by splitting up dominant owner's generation assets to increase the number of competitors and to enhance intensity of the competition. England and Wales, Germany, Italy, California and Australia are samples of the electricity markets where this structural remedy has been employed. Both empirical research and economic theory confirmed that this competition policy can intensify the competitiveness, reduce prices and increase social welfare (Hirschhausen et al., 2007; Green, 1996; Day and Bunn, 2001; Borenstein and Bushnell, 1999; Bushnell, 2003).

Choosing a desirable divestiture policy has been always a complex problem for regulatory authorities and policy makers. In order to suggest a practical solution to this problem, behavior of the electricity market is simulated to analyze effects of different divestiture policies before implementation. As an example, the approach of linear supply function (SF) with symmetric ownership structure is applied to analyze the effects of first order of capacity divestiture policy on the behavior of England and Wales market, which was proposed by the UK office of electricity regulation (OFFER) in 1994 (Green, 1996). A computational approach is developed (Day and Bunn, 2001) to study the 
efficiency of second order of capacity divestiture policy (OFFER in 1999). The authors conclude that this competition policy can increase the intensity of competition, but the regulatory task for monitoring and controlling uncompetitive behavior in short run plays a vital role in reducing the market power abuse. The behavior of California electricity market is simulated using Cournot model for scenarios of partial and full divestiture of Southern California Edison and San Diego gas and electric companies (Borenstein and Bushnell, 1999). Despite positive impacts of the divestiture policy on reduction of market power, the simulation results have indicated the price responsiveness of demand may have more effective influence in controlling the market price in short term. The Cournot model is also applied (Bushnell, 2003) to examine the potential impacts of further divestiture in California. Applying the divestiture policy, cost of the market power is reduced by about $40 \%$.

Market concentration analysis and market simulation are two important methods that have been used for ex-ante analysis of structural changes in the electricity industry. The former is usually applied as first step of analysis, especially in situations where the cost data of generators are unknown (Borenstein and Bushnell, 1999). In this way, the concentration measures indicate the ex-ante global potential of the market power using information related to the generation capacity of producers. The consultancy firm "London Economics" evaluates the structure of six European electricity markets based on available installed capacity (London Economics, 2007). The average value of Herfindahl-Hirschman Index (HHI) indicates that England and Germany are the least concentrated markets among the studied cases. The market share of firms and the values of $\mathrm{HHI}$ in England and Wales were calculated on the basis of operational capacity of their plants portfolio before 1996 and after two divestiture policies applied in 1996 and 1999 (Bunn and Martoccia, 2005).

The ex-ante analysis using this method avoids operation conditions such as load/generation capacity distribution in the network, transmission limitation and market participants' behavior. Even though almost all of the concentration measures are static and cannot take into account dynamic property related to the operation conditions, as a first screen of the market power, they can provide insight about the intensity of competitiveness. Now an important question arises, which is in situations where the cost data of generators are unknown, how the impacts of the operation conditions on the market concentration can be taken into account?

When the costs of generators and network information are known, the market participants' strategic behavior can be modeled to simulate the electricity market. Game theory such as Cournot and supply function equilibrium is a famous approach that has been used by researchers to model the strategic behavior. In spite of advantages of the game theory in the market simulation, this method cannot capture some human peculiarities such as learning and intelligence. Nowadays developed intelligent methods have made possible modeling of more sophisticated features in human decision making. Agent-based computational economics (ACE) is indeed created by application of these methodologies in modeling economic process as a dynamic complex system. The existing literature indicates that the ACE is a powerful tool for the ex-ante analysis of market power, and consequently for policy makers in evaluating structural changes and market policies. The suppliers and consumers' behaviors under the New Electricity Trading Arrangement in England and Wales electricity market were studied based on reinforcement learning (RL) method (Bunn and Oliveira, 2001). They tried to model the interactions between the bilateral market and balancing mechanism. The effects of agent's behavior and market structure on the market power are analyzed by finding the equilibrium point using the Roth-Erev algorithm (Nicolaisen et al., 2001). A simulation framework is designed using agentbased modeling of electricity systems to test the Wholesale Power Market Platform proposed by the US Federal Energy Regulatory Commission (Sun and Tesfatsion, 2007). The supplier agent's bidding problem is modeled as a self-play problem using the Q-Learning (QL) algorithm, and its performance is compared with that of proposed model-based approach (Rahimiyan and Rajabi Mashhadi, 2008). Also, the effect of the power suppliers' market power on their bidding strategies is evaluated under pay as bid auction in the Iran electricity market. Using computer-based agents, the behavior of California electricity market under Automatic Mitigation Procedure proposed by the independent system operator (ISO) as market power limitation rule has been studied (Entriken and Wan, 2005). An agent-based simulator is designed using the QL algorithm to evaluate the market behavior in real condition in comparison with the competitive benchmark under three different congestion management schemes, i.e. (1) locational marginal pricing (LMP), (2) market splitting and (3) flow-based market coupling (Krause and Andersson, 2006). An RLbased approach is utilized (Nanduri and Das, 2007) to analyze the market power in the day-ahead energy markets operated under uniform price, discriminatory and second-price uniform auctions.

The aim of this research work is to evaluate the effects of divestiture policy of dominant firms' generation assets on increase of market competitiveness. An analytical method, as a first approach, is introduced to determine variation of the market concentration with respect to different producers' bidding strategies. To accomplish this, a concentration boundary (CB) problem is designed. The objective function of this problem is to minimize or maximize the market concentration in such a way that network constraints are satisfied. Using this method, an interval for the utilized concentration measure is obtained. Thus, the policy maker can evaluate the effect of divestiture policy on the range of the market concentration, and select the desired strategy to foster competition. This approach is especially useful for the policy maker in situations where the cost function of generators is unknown.

The ACE as a second approach is used to provide a computational framework for simulating the behavior of the electricity market under operation condition. In this computational framework, the market participants' learning behavior is modeled using the QL method. The market participant using the QL algorithm learns how to respond in competing with rivals to maximize the long-run profit. This makes it possible to study the effect of divestiture policy on market competitiveness considering the power suppliers' strategic behavior in exercising the market power. Both of the mentioned methods are applied for evaluating different divestiture policies in a multi-area power system and the obtained results are compared.

The structure of paper is organized as follows. In Section 2, the proposed analytical method is developed. In Section 3, the agentbased computational modeling of the electricity market is designed. In Section 4, the effects of the divestiture policy of generation assets on the market behavior are studied. In Section 5, the obtained results are presented.

\section{Analytical method}

\section{1. $C B$ problem}

The idea is to determine the range of variation of concentration measure. As mentioned in the introduction, the degree of market concentration is a symptom of system-wide market power. The $\mathrm{HHI}$ is also the most popular concentration measure. For a specific 
market structure, the value of HHI corresponding to the operation condition strongly depends on the power suppliers' bidding strategies. In other words, the electricity market may experience different values of $\mathrm{HHI}$ for different scenarios of the power suppliers' bidding strategies. In principle when it is not possible to model the market participants' strategic behavior, determination of minimum and maximum values of HHI can be a good solution for the ex-ante analysis of market competitiveness. To accomplish this, the $C B$ problem is designed to determine the boundary values of $\mathrm{HHI}$ for a specific market structure.

The range of HHI can be interpreted as an indicator of market competitiveness. The $\mathrm{HHI}$ ranges from zero value in perfect competition to 10,000 in monopolistic condition. Based on two critical values of HHI, US Department of Justice and the Federal Trade Commission (US DOJ/FTC, 1997) categorized the markets into three groups; unconcentrated $(\mathrm{HHH}<1000)$, moderately concentrated $(1000<\mathrm{HHI}<1800)$ and highly concentrated $(1800<\mathrm{HHI})$. According to this regulation and knowing the determined interval of $\mathrm{HHI}$, the policy maker can get useful information concerning the district of competition in which the market lies.

\subsection{Mathematical formulation}

In order to determine the boundary values of $\mathrm{HHI}$, at first, we should understand how dispatched power of generating units is computed in the operation condition. This is done by solving the market clearing problem formulated below. In the market clearing problem, the objective function is to maximize social welfare subject to load flow equality constraints and operational limits.

$\max : \quad .5 G^{T} C_{s f} G-G^{T} B_{s f}$

s.t.

$\mathrm{e}^{\mathrm{T}}(\mathrm{G}-\mathrm{D})=0$

$0 \leq \mathrm{G} \leq \mathrm{G}_{\max }$

$-\mathrm{P}_{1}^{\max } \leq \mathrm{PTDF}(\mathrm{G}-\mathrm{D}) \leq \mathrm{P}_{1}^{\max }$

where $\mathrm{C}_{\mathrm{sf}}$ and $\mathrm{B}_{\mathrm{sf}}$ are diagonal matrixes of the slope and the vector of intercept of the offered supply functions, respectively, e is the vector with all ones, $D$ and $G$ are, respectively, vectors of active load and dispatched power and $G_{\max }$ is the vector of generation capacity limit; $P_{1}^{\max }$ and PTDF are vectors of maximum line flow limits and matrix of power transfer distribution factors, respectively. The PTDF is calculated based on the sensitivity analysis in DC power flow model (Wood and Wollenberg, 1996).

Corresponding to each scenario of power suppliers' bidding strategies, the vector $G$ as solution of the above optimization problem is obtained. Thus, related to the bidding strategies, the vector $G$ and the power suppliers' market shares can vary in a feasible set of the market clearing problem. Clearly, the HHI can also experience different values bounded by the feasible set of the market clearing problem. This implies the boundary values of $\mathrm{HHI}$ can be computed by solving the $\mathrm{CB}$ problem in which the function of $\mathrm{HHI}$ is minimized or maximized subject to the constraints given in the market clearing problem. The mathematical formulation of the $\mathrm{CB}$ problem for computing the minimum and maximum values of $\mathrm{HHI}$ is given as

$$
\min _{\mathrm{G}} k u(\mathrm{TG})^{\mathrm{T}}(\mathrm{TG}) \quad \text { where } k=\frac{10,000}{\left(\sum_{i=1}^{N_{\mathrm{b}}} \mathrm{D}_{i}\right)^{2}} \quad \text { s.t. }
$$

$\mathrm{e}^{\mathrm{T}}(\mathrm{G}-\mathrm{D})=0$

$0 \leq \mathrm{G} \leq \mathrm{G}_{\max }$

$-\mathrm{P}_{1}^{\max } \leq \mathrm{PTDF}(\mathrm{G}-\mathrm{D}) \leq \mathrm{P}_{1}^{\max }$

where $u$ can be set as 1 and -1 for computation of minimum and maximum values of $\mathrm{HHI}$, respectively, $\mathrm{T}$ is the transformation matrix with dimension $N_{\mathrm{S}} N_{\mathrm{G}}, N_{\mathrm{S}}$ and $N_{\mathrm{G}}$ are the number of power suppliers and generating units, respectively, $D_{i}$ is the active load in bus $i$ and $N_{\mathrm{b}}$ the number of buses.

The elements of matrix $\mathrm{T}$ are 0 or 1 . The elements in row $i$ of matrix $\mathrm{T}$ whose values equal 1 represent the generating units that the power supplier $i$ owns. Thus, the vector $G$ multiplied by matrix $\mathrm{T}$ denotes how much power is generated by each power supplier's generating units. Clearly, if each supplier owns only one generating unit, the matrix $\mathrm{T}$ is an identity matrix and $\mathrm{T}$ multiplied by $G$ equals the vector $G$. It should be noted that the divestiture policy changes the structure of matrix $T$. Thus, evaluation of divestiture policy needs the arrangement of elements of this matrix.

The feasible set of the market clearing problem is exactly the same as the feasible set of the $\mathrm{CB}$ problem. As a result, it is trivial that the range of $\mathrm{HHI}$ determined by the proposed analytical method certainly encompasses the value of $\mathrm{HHI}$ corresponding to the operation condition.

\subsection{Solving the $C B$ problem}

In order to solve the $\mathrm{CB}$ problem, the Lagrangian function can be written as follows:

$$
\begin{aligned}
\mathrm{L}\left(\mathrm{G}, \lambda, \mu_{\mathrm{G}, \min }, \mu_{\mathrm{G}, \max }, \mu_{1, \min }, \mu_{\mathrm{l}, \max }\right) \\
=k u(\mathrm{TG})^{\mathrm{T}}(\mathrm{TG})-\lambda e^{\mathrm{T}}(\mathrm{G}-\mathrm{D})+\mu_{\mathrm{G}, \min }{ }^{\mathrm{T}} \mathrm{G}-\mu_{\mathrm{G}, \max }{ }^{\mathrm{T}}\left(\mathrm{G}-\mathrm{G}_{\max }\right) \\
\quad+\mu_{1, \min }{ }^{\mathrm{T}}\left(\mathrm{P}_{1}{ }^{\max }+\mathrm{PTDF}(\mathrm{G}-\mathrm{D})\right)-\mu_{1, \max }{ }^{\mathrm{T}}\left(\mathrm{PTDF}(\mathrm{G}-\mathrm{D})-\mathrm{P}_{1}^{\max }\right)
\end{aligned}
$$

where $\lambda \in \mathfrak{R}, \mu_{\mathrm{G}, \text { min }} \in \mathfrak{R}^{N_{\mathrm{G}}}, \mu_{\mathrm{G}, \text { max }} \in \mathfrak{R}^{N_{\mathrm{G}}}, \mu_{\mathrm{l}, \text { min }} \in \mathfrak{R}^{N_{1}}$ and $\mu_{\mathrm{l}, \text { max }} \in \mathfrak{R}^{N_{1}}$ are vectors of Lagrange multipliers corresponding to equality constraint, and lower and upper bounds on generation and transmission flow, respectively.

Computing the gradient of the Lagrangian function with respect to the variables $G, \lambda, \mu_{G, \min }, \mu_{G, \max }, \mu_{1, \min }$ and $\mu_{1, \max }$, the first-order necessary optimality conditions known as KarushKuhn-Tucker (KKT) for the CB problem are obtained as follows:

$\nabla_{\mathrm{G}} L\left(\mathrm{G}, \lambda, \mu_{\mathrm{G}, \min }, \mu_{\mathrm{G}, \max }, \mu_{1, \min }, \mu_{\mathrm{l}, \max }\right)=0$

$\mathrm{e}^{\mathrm{T}}(\mathrm{G}-\mathrm{D})=0$

$-\mathrm{G} \leq 0, \quad 0 \leq \mu_{\mathrm{G}, \min }, \quad \mu_{i, \mathrm{G}, \min } \mathrm{G}_{i}=0 \quad \forall i$

$\mathrm{G}-\mathrm{G}_{\max } \leq 0, \quad 0 \leq \mu_{\mathrm{G}, \max }, \quad \mu_{i, \mathrm{G}, \max }\left(\mathrm{G}_{i}-\mathrm{G}_{i, \max }\right)=0 \quad \forall i$

$-\mathrm{P}_{1}^{\max }-\operatorname{PTDF}(\mathrm{G}-\mathrm{D}) \leq 0, \quad 0 \leq \mu_{1, \min }$,

$$
\mu_{i, 1, \min }\left(\mathrm{P}_{i, 1}{ }^{\max }+\operatorname{PTDF}_{i}(\mathrm{G}-\mathrm{D})\right)=0 \quad \forall i
$$

$\operatorname{PTDF}(G-D)-P_{1}^{\max } \leq 0, \quad 0 \leq \mu_{1, \max }$,

$$
\mu_{i, 1, \max }\left(\operatorname{PTDF}_{i}(\mathrm{G}-\mathrm{D})-\mathrm{P}_{i, 1} \max ^{\max }\right)=0 \quad \forall i
$$

where $\mathrm{PTDF}_{i}$ is the $i$ th row of matrix PTDF.

As seen from Eqs. (3) and (4), vector $G$ is the only variable of the $C B$ problem and all constraints are linearly dependent on this. Thus, the feasible set of this optimization problem is a convex set. The Hessian matrix of the objective function equals the symmetric matrix $2 k u \mathrm{~T}^{\mathrm{T}} \mathrm{T}$. It is demonstrated in linear algebra theory that a symmetric matrix in the form $\mathrm{T}^{\mathrm{T}} \mathrm{T}$ is always positive semi-definite (Chen, 1999). If the value of $u$ equals 1 , the Hessian 
matrix $2 k \mathrm{~T}^{\mathrm{T}} \mathrm{T}$, with $k>0$, is also positive semi-definite, and therefore the objective function of the $\mathrm{CB}$ problem is convex. If $u$ equals -1 , obviously the Hessian matrix is negative semidefinite on the feasible set, and consequently the objective function is non-convex.

According to the basic theorem in convex optimization if the objective function and the feasible set in an optimization problem are convex, then any points that satisfy the KKT conditions are also the global optimal solution (Chong and Zak, 2001). Therefore, a vector $G^{*}$ that meets the KKT conditions of the $C B$ problem for $u=1$ is the global optimal solution for computation of the minimum value of HHI. The minimum value of $\mathrm{HHI}$ can be found easily using quadratic programming method. In contrast, for $u=-1$, determination of the maximum value of $\mathrm{HHI}$ requires solving a non-convex objective function. In this condition, stochastic optimization methods like genetic algorithm are wellknown techniques to handle non-convex problems.

\section{Agent-based computational approach}

\subsection{Structure of $A C E$}

In situations where the cost data of generating units and network information are available, the ACE as a powerful tool in modeling the behavior of the electricity market can be used. The ACE is a computational study of economic processes modeled as dynamic systems comprised of interacting agents (Tesfatsion and Judd, 2006). In the ACE, in fact a bottom-up approach is employed to model the economic systems in such a way that dynamic interdependency of micro (agent's behavior) and macro (overall behavior of market) structures is established (Tesfatsion, 2002).

Generally, the framework of the electricity market is created through architecture of energy market, operating rules, market structure and market agents (Stoft, 2002). In this study, the ACE framework for modeling the competitive energy market is also configured by the mentioned parts as follows:

(1) Architecture of energy market-hour-ahead energy market in the pool-based wholesale electricity market is considered.

(2) Operating rules-in the market clearing mechanism, the objective function is to maximize social welfare subject to the load flow equality constraints and operational limits. The energy market is settled by executing the congestion management scheme based on the LMP method (Gan and Bourcier, 2002).

(3) Market structure - the demand is assumed to be inelastic. The dispatched power flows through transmission lines with limited capacity based on DC power flow model. The ownership structure of generation assets is also considered.

(4) Market agents - the regulatory authority monitors the electricity market and keeps it under surveillance. The ISO operates the electricity market to be healthy and secure. The power distribution agents (PDAs) demand the required energy to supply customers. The power supplier agents (PSAs) own generating units. Each PSA is an intelligent agent who chooses the best strategy in competition with rivals by learning from past experiences. In the introduced ACE structure, each PSA's learning behavior is modeled using QL algorithm applied by the authors (Rahimiyan and Rajabi Mashhadi, 2008).

In an artificial environment, the market is operated as follows. In the hour-ahead electricity market, PSAs compete among themselves by offering the supply function for each own generating unit associated with the lower and upper bounds of

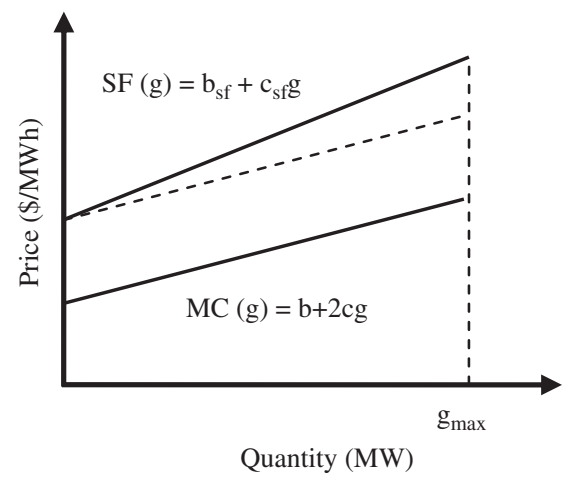

Fig. 1. Supply function and marginal cost of PSA's generating unit.

production as feasible production interval for an hour. The PSAs can utilize the market power through financial and physical withholding. Obviously, each agent may choose strategic bidding by deviating the slope $\left(c_{\mathrm{sf}}\right)$ or intercept $\left(b_{\mathrm{sf}}\right)$ of supply function (SF) from its corresponding coefficients of marginal cost (financial withholding) and the feasible production interval from the true interval (physical withholding). In this paper, by neglecting physical withholding, it is assumed that each agent bids zero value and the maximum capacity of generating unit $\left(g_{\max }\right)$ as lower and upper limits of generation for each hour, respectively. The schematic diagram of strategic bidding is illustrated in Fig. 1.

The ISO receives the bids and forecasted demands from PSAs and PDAs, respectively. Then, the ISO clears the market by solving the market clearing problem as given in the previous section. At the end of each trading hour, the PSAs are informed of the dispatched power of own generating units and the LMP.

\subsection{Computational modeling of PSA's behavior}

The bidding problem is a major issue from each PSA's viewpoint. Each PSA attempts to select a suitable bidding strategy for own generating units in such a way that the accumulated profit is maximized in the long run. In this situation, the ability for learning is one of the important human's attributes, and should be noticed in modeling PSA's behavior. Review of related researches shows that the QL is a useful computational approach to solve PSA's profit maximization problem considering the aforementioned feature.

The QL is a model-free type of RL and was introduced by Watkins (1989). Generally, the RL problem is the learning problem for an agent interacting with an environment to achieve the goals. In the RL, the environment is generally identified through a set of states. An agent interacts with the environment selecting an action among admissible action set. In the QL algorithm for each admissible state-action pair $(s, a)$, the value function is defined as a $Q$-value. The $Q(s, a)$ is indeed the long term reward expected to be acquired over the future starting from the state-action pair $(s, a)$. In each state of environment, the agent evaluates how good the taken action is considering the immediate reward and maximum estimated $Q$-value for new states (Sutton and Barto, 1998).

In the ACE structure, each agent using the QL method tries to learn from experiences obtained by participating in the electricity market repeatedly. The accumulated experiences are utilized to identify implicitly the agent's local market power, and as a result to find better response in competing with the rivals. The QL-based computational framework can not only take actual cost function and asymmetric ownership structure but also model human's learning process in making decision. In this artificial environment, 
each agent can make decision independently and intelligently based on the available incomplete information.

In the ACE structure, in order to find each PSA's bidding strategy for each hour, the computational algorithm of the QL is presented as follows:

(1) State identification - the state of environment for the current step is the publicly available LMP of previous step obtained by solving the market clearing problem.

(2) Action selection-after obtaining the current state $\left(s_{t}\right)$, the PSA uses its $Q$-value lookup table, which saves the $Q$-values $(Q(s, a))$ for each state-action pair. The action selection through the QL algorithm is done by choosing the action with maximum $Q$-value in the current state. To trade off between exploitation and exploration, the PSA can utilize from the $\varepsilon$-greedy strategy. It means that the PSA selects the action that has the maximum $Q$-value with high probability $(1-\varepsilon)$ and an arbitrary action from all admissible actions with small probability $\varepsilon$, independent of the $Q$-values.

(3) Q-value update-at the end of each step and after being notified of the new LMP and dispatched power of own generating units, the PSA calculates its total benefit as a reward $r_{t+1}$ and then updates its $Q$-value according to

$Q_{t+1}\left(s_{t}, a_{t}\right)=Q_{t}\left(s_{t}, a_{t}\right)+\alpha \Delta Q\left(s_{t}, a_{t}\right)$

$\Delta Q\left(s_{t}, a_{t}\right)=r_{t+1}+\gamma \max _{a^{\prime}} Q\left(s_{t+1}, a^{\prime}\right)-Q_{t}\left(s_{t}, a_{t}\right)$

where $\alpha$, the agent's learning rate, can be interpreted as the extent by which estimated $Q$-values are updated by new data; $\gamma$ is the discounted factor, which measures how much the expected future reward is important.

\section{Evaluation of divestiture policy}

In this section, both methods are applied to evaluate effects of several divestiture policies on a multi-area power system illustrated in Fig. 2. In the studied electricity market, four PSAs compete with each other. The data of the ownership structure are

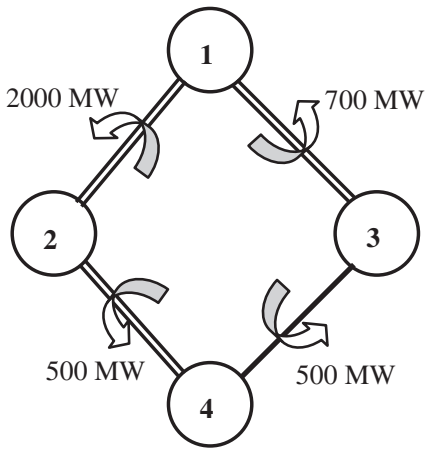

Fig. 2. Multi-area power system. given in Table 1 (see the Appendix). The vector [2300,4000,3000, 1800] MW shows the value of load for the areas.

We analyze the competitiveness of the electricity market under initial structure (first option) in which no divestiture is executed plus two divestiture policies. In the second option, PSA 2 sells generating units 5 and 6 to new PSA 5. In the third option, in addition to the previous structural change, generating unit 12 is also separated from PSA 4 by new PSA 6, and so there are six PSAs. The three mentioned divestiture options are assessed using the proposed analytical method and the ACE approach.

\subsection{Analysis of concentration boundaries}

In this subsection, the analytical method is employed to evaluate effects of the mentioned policies on concentration boundaries. The analytical method determines the maximum and minimum values of $\mathrm{HHI}$ for each option. Consequently, we can understand how much a divestiture policy may move down the boundary values of $\mathrm{HHI}$ before implementation.

In the analytical method, the effect of each divestiture policy on the boundary values of $\mathrm{HHI}$ is taken into account through the change of structure of matrix $\mathrm{T}$ in the $\mathrm{CB}$ problem. The structure of matrix $\mathrm{T}$ is presented in Fig. 3 for three divestiture options. The values of $\mathrm{HHI}_{\max }$ and $\mathrm{HHI}_{\text {min }}$ for three options are shown in Fig. 4. According to this figure, the determined interval for $\mathrm{HHI}$ lies above the threshold value 1800 , and hence the electricity market based on DOJ/FTC's regulation is highly concentrated under three divestiture options. It should be noticed that the second and third options have moved down the values of $\mathrm{HHI}_{\max }$ and $\mathrm{HHI}_{\min }$ in such a way that the value of $\mathrm{HHI}_{\text {min }}$ has approached the threshold value 1800 , i.e. upper boundary of moderately concentrated condition.

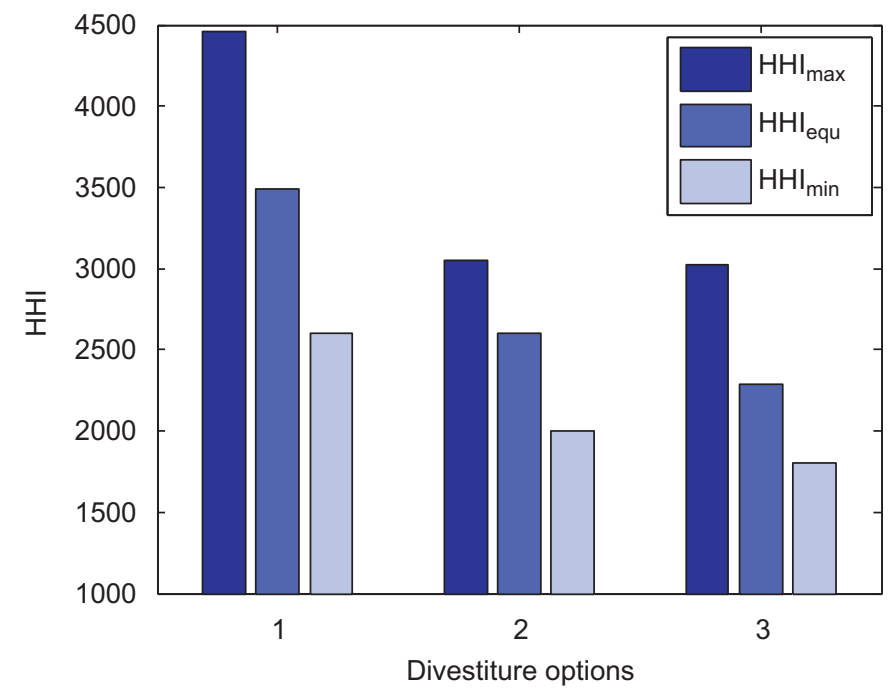

Fig. 4. Values of $\mathrm{HHI}_{\min }, \mathrm{HHI}_{\max }$ and $\mathrm{HHI}_{\text {equ }}$ for three divestiture options.

$$
T_{F O}=\left[\begin{array}{l}
111000000000 \\
0001111100000 \\
0000000011100 \\
0000000000011
\end{array}\right] T_{S O}=\left[\begin{array}{l}
1110000000000 \\
000100100000 \\
000000011100 \\
000000000011 \\
000011000000
\end{array}\right] T_{T O}=\left[\begin{array}{l}
111000000000 \\
000100100000 \\
000000011100 \\
000000000010 \\
000011000000 \\
000000000001
\end{array}\right]
$$

Fig. 3. Structure of the matrix $\mathrm{T}$ for three divestiture options. 
In accordance with the given ownership structure of the first option, PSAs 2 and 4 own $46.5 \%$ and $15.7 \%$ of generation capacity, respectively. Thus, it is expectable that the second option has significant effect on the reduction of values of $\mathrm{HHI}_{\max }$ and $\mathrm{HHI}_{\min }$. However application of the third divestiture cannot cause any noticeable decrease in the boundary values of the market concentration more than the second option.

\subsection{Behavioral analysis}

In this subsection, the ACE as complex adaptive modeling of the electricity market is used to analyze the market behavior under three divestiture policies. The behavior of electricity market is simulated for 1500 iterations. The value of $\mathrm{HHI}$ corresponding to the market equilibrium ( $\mathrm{HHI}_{\text {equ }}$ ) can be obtained. As seen from Fig. $4, \mathrm{HHI}_{\text {equ }}$ is limited by the boundary values of $\mathrm{HHI}$ for all options. This confirms the usefulness of the proposed analytical method for ex-ante analysis of the market power.

The average values of LMP for three divestiture options are presented in Fig. 5. It is shown that the second option has reduced considerably the average value of LMP in areas 1 and 2, while, the average value of LMP in area 4 has not changed by this competition policy. In order to solve this issue, it would be beneficial to divest PSA 4's generation assets. As seen from Fig. 5, application of third option has not only reduced the LMP in areas $1-3$, but also diminished the LMP in area 4 . This results from the concept of local market power, which may be used to divide the electricity market into some geographic markets. To clarify this event, the value of LMP in area 4 is presented during market simulation in Figs. 6-8. Before any divestiture policy performed, PSA 4 abuses the local market power created by transfer limitation of the lines connecting area 4 to the network. In this situation, PSA 4 tries to create congestion in the aforementioned lines, and raises the LMP to the ceiling price, i.e. $100 \$ / \mathrm{MWh}$ (see Fig. 6). As obvious in Fig. 7, the divestiture of PSA 2's generation assets in the second option cannot reduce PSA 4's market power and the LMP in area 4, although application of third option has increased the level of competition in area 4 and reduced the value of LMP according to Fig. 8.

Quantitative analysis of power flow through the lines connecting area 4 to the network can give useful information about

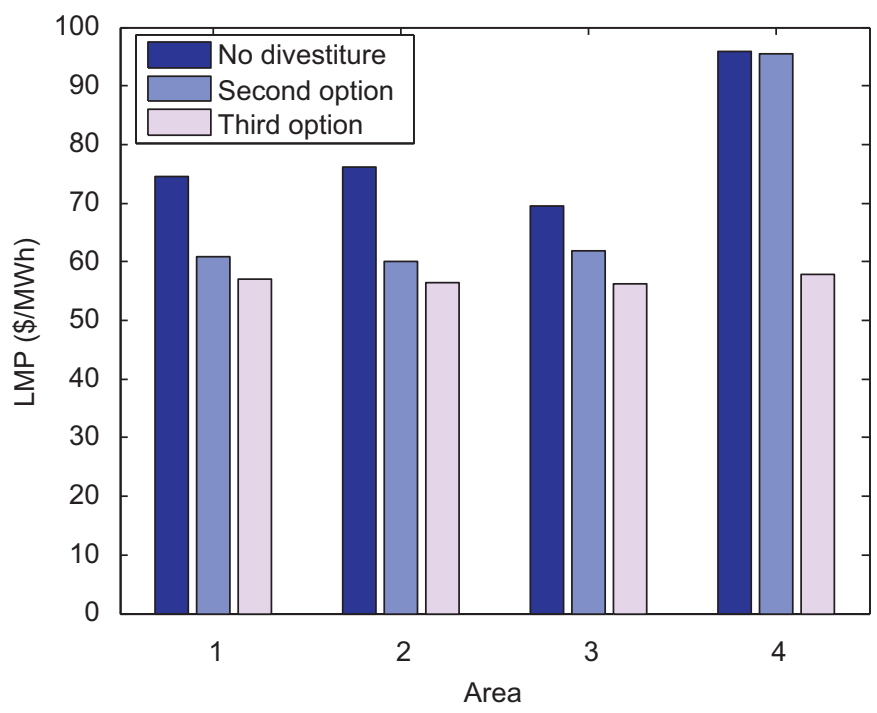

Fig. 5. Average value of the LMP corresponding to the market equilibrium for three divestiture options.

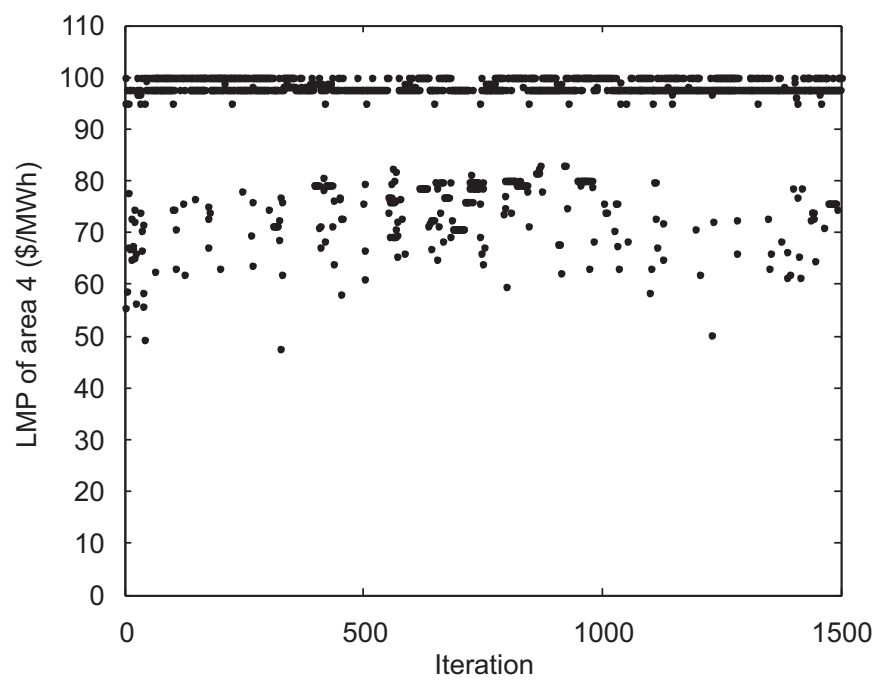

Fig. 6. Value of the LMP of area 4 in the first option.

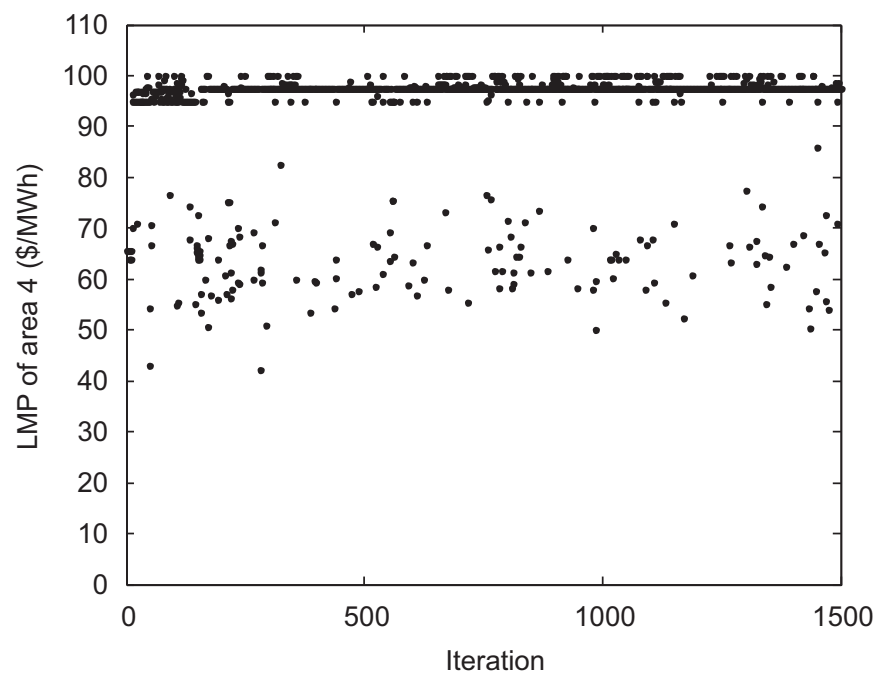

Fig. 7. Value of the LMP of area 4 in the second option.

how the divestiture options have influenced on the exercise of market power in this area. According to the data obtained during simulation, the empirical complementary cumulative distribution function (CCDF) of power flow of the lines is presented in Figs. 9 and 10 for three divestiture options. The empirical CCDF shows how often the value of power flow of a line is above a particular level. The probability of congestion of each line is defined as the probability that the transmitted power equals its limitation, and is easily obtained from the empirical CCDF. As seen from Figs. 9 and 10 , in the first option, the probabilities of congestion for the lines connecting area 2 to 4 and area 3 to 4 are 0.45 and 0.85 , respectively. This means that the transmission congestion has fragmented the studied market into two geographic markets in most iterations such that PSA 4 has exercised the local market power to increase the LMP in area 4. Both figures indicate that the usage of second divestiture policy has moved the empirical CCDF upward in comparison with the initial state. Even in the second option, the probability of congestion of the lines connecting area 2 to 4 has increased to 0.9 . In other words, increase of the competition level in area 2 enhances the probability of loadability and congestion of the lines, and cannot reduce PSA 4's local 


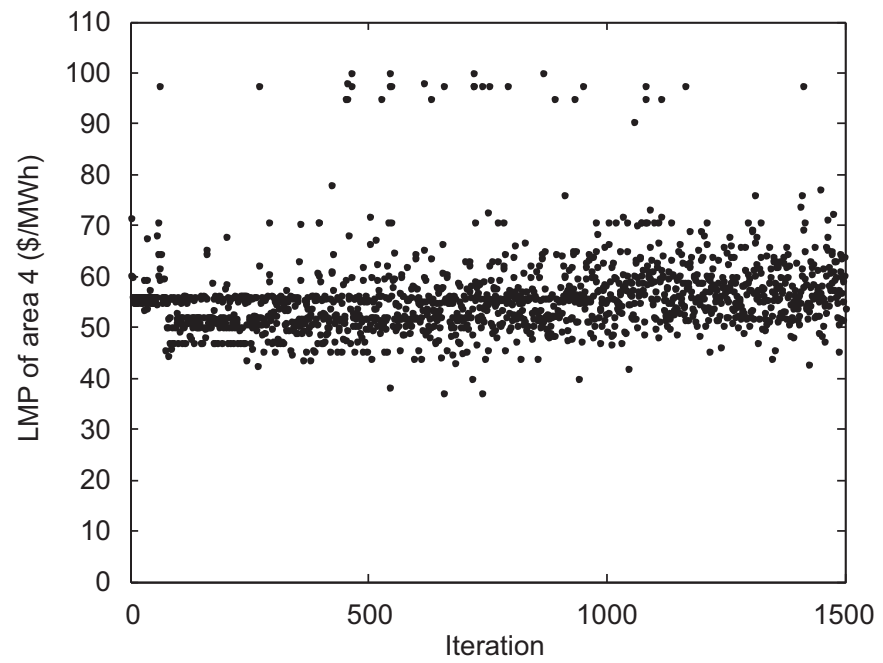

Fig. 8. Value of the LMP of area 4 in the third option.

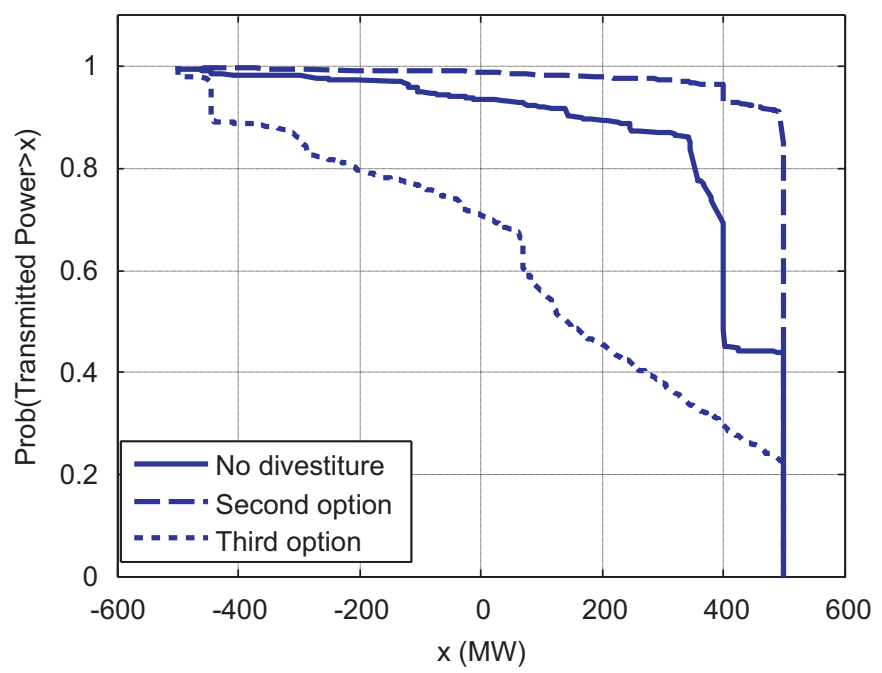

Fig. 9. Empirical CCDF of power flowing from area 2 to 4 through the lines with capacity $500 \mathrm{MW}$

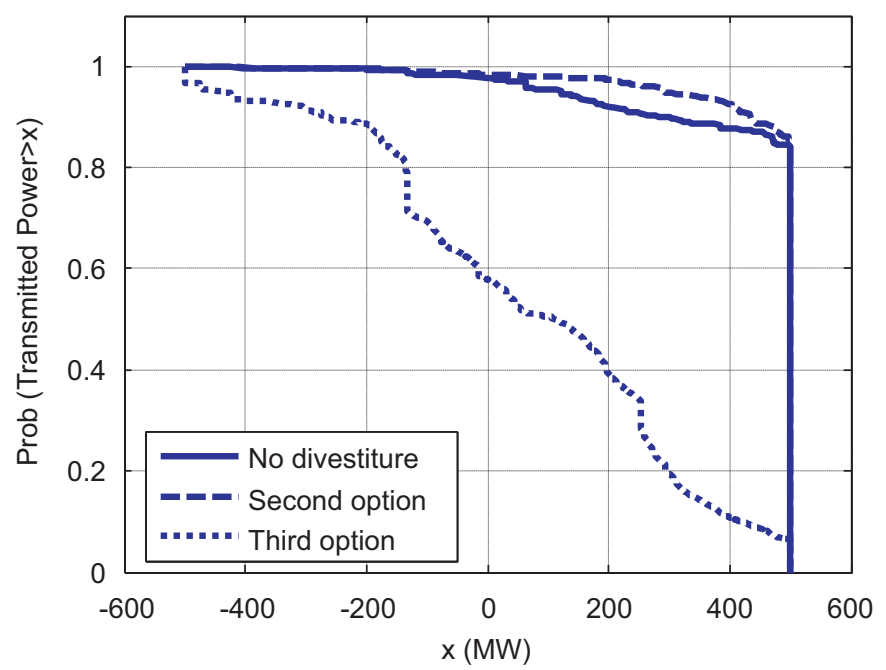

Fig. 10. Empirical CCDF of power flowing from area 3 to 4 through the line with capacity $500 \mathrm{MW}$. market power. This implies that the increase of competition level in area 4 can be a useful strategy to relieve the transmission congestion. Comparison of the empirical CCDF of power flow of lines for three options clearly illustrates that their probability of loadability and congestion has reduced in the third divestiture option.

The simulation results in Fig. 4 clarify that the analytical method cannot indicate the aforementioned advantage of third option in comparison with the second option since the analytical method evaluates the global market power and cannot take into account effects of the local market power. Consequently, in order to select an effective divestiture policy, both global and local market power should be evaluated. Focusing on this notion, in addition to a dominant firm with high market share, a firm with medium market share and also high local market power may be a desired alternative for divestiture.

\section{Conclusions}

Since the establishment of competitive energy markets, choosing suitable competition policies has been a main problem that policy makers have encountered. In this paper, an analytical method is proposed for an ex-ante evaluation of divestiture policy of power suppliers' generation assets. The important advantage of the proposed method is that it can be used even for situations where data of cost function of generating units are not available. Another strong point is that the value of HHI corresponding to operation condition is certainly viable in the interval determined by this method. However, since the method assesses the global market power, effects of local market power may not be taken in evaluating the effectiveness of some divestiture policies.

To cover this shortcoming, for situations where the cost data of generating units are known, the agent-based computational economics approach is used to model the power supplier's strategic behavior. The computational modeling of the electricity market can reveal effects of exercising the local market power. The simulation results show that the transmission constraints can create geographic markets where it is possible for some firms with even medium or small market share to raise prices. Thus, in addition to large firms, firms with considerable local market power can also be noticed to apply desired divestiture policy.

\section{Appendix}

See Table 1

Table 1

Data of generation units and ownership structure.

\begin{tabular}{|c|c|c|c|c|c|c|}
\hline \multirow[t]{2}{*}{ Area } & \multirow[t]{2}{*}{ PSA } & \multirow[t]{2}{*}{ Generating unit } & \multirow[t]{2}{*}{ Capacity (MW) } & \multicolumn{3}{|c|}{ Cost functions } \\
\hline & & & & $a$ & $b$ & $c$ \\
\hline \multirow[t]{3}{*}{1} & 1 & 1 & 500 & 0 & 10 & 0.004 \\
\hline & & 2 & 500 & 0 & 15 & 0.006 \\
\hline & & 3 & 1000 & 0 & 50 & 0.008 \\
\hline \multirow[t]{4}{*}{2} & 2 & 4 & 2500 & 0 & 12 & 0.005 \\
\hline & & 5 & 2000 & 0 & 15.5 & 0.006 \\
\hline & & 6 & 2000 & 0 & 15.5 & 0.007 \\
\hline & & 7 & 1500 & 0 & 21.5 & 0.008 \\
\hline \multirow[t]{3}{*}{3} & 3 & 8 & 1500 & 0 & 16 & 0.006 \\
\hline & & 9 & 1500 & 0 & 14 & 0.005 \\
\hline & & 10 & 1500 & 0 & 13 & 0.004 \\
\hline \multirow[t]{2}{*}{4} & 4 & 11 & 700 & 0 & 16 & 0.006 \\
\hline & & 12 & 2000 & 0 & 31 & 0.009 \\
\hline
\end{tabular}




\section{References}

Borenstein, S., Bushnell, J., 1999. An empirical analysis of the potential for market power in California's electricity industry. The Journal of Industrial Economics 47, 285-323.

Borenstein, S., Bushnell, J., Wolak, F., 2002. Measuring market inefficiencies in California's restructured wholesale electricity market. American Economic Review 92, 1376-1405.

Bower, J., Bunn, D.W., Wattendrup, C., 2001. A model-based analysis of strategic consolidation in the German electricity industry. Energy Policy 29, 987-1005.

Bunn, D., Martoccia, M., 2005. Unilateral and collusive market power in the electricity pool of England and Wales. Energy Economics 27, 305-315.

Bunn, D.W., Oliveira, F.S., 2001. Agent-based simulation: an application to the New Electricity Trading Arrangements of England and Wales. IEEE Transactions on Evolutionary Computation 5, 493-503.

Bushnell, J., 2003. Looking for trouble: competition policy in the U.S. electricity industry. In: Griffin, J., Puller, S. (Eds.), Electricity Deregulation: Choices and Challenges. University of Chicago Press, Chicago.

Chen, C.T., 1999. Linear System Theory and Design. Oxford University Press.

Chong, E., Zak, S. , 2001. An Introduction to Optimization. John Wiley \& Sons.

Day, C.J., Bunn, D.W., 2001. Divestiture of generation assets in the electricity pool of England and Wales: a computational approach to analyzing market power. Journal of Regulatory Economics 19, 123-141.

Domanico, F., 2007. Concentration in the European electricity industry: the internal market as solution? Energy Policy 35, 5064-5076.

Entriken, R., Wan, S., 2005. Agent-based simulation of an automatic mitigation procedure. In: IEEE Proceedings of the 38th Annual Hawaii International Conference on System Sciences, HICSS 05, p. 92c.

Gan, D., Bourcier, D.V., 2002. Locational market power screening and congestion management: experience and suggestions. IEEE Transactions on Power Systems 17, 180-185.

Green, R., 1996. Increasing competition in the British electricity spot market. The Journal of Industrial Economics 44, 205-216.

Hirschhausen, C.V., Neumann, A., Weigt, $\mathrm{H}$, 2007. Divestiture as an instrument of a pro-active competition policy: conceptual issues and lessons from international experiences. Chair of Energy Economics and Public Sector Management Dresden University of Technology.

Krause, T., Andersson, G., 2006. Evaluating congestion management schemes in liberalized electricity markets using an agent-based simulator. In: Proceedings of the Power Engineering Society General Meeting.

London Economics, 2004. Structure and functioning of the electricity market in Belgium in a European perspective. Prepared for General Council of the CREG.
London Economics, 2007. Structure and performance of six European wholesale electricity markets in 2003, 2004 and 2005. London Economics in association with Global Energy Decisions.

Matthes, F.C., Poetzsch, S., Grashoff, K., 2005. Power generation market concentration in Europe 1996-2004: an empirical analysis, Report No. 2005012-en. ÄOko-Institut e.V., Berlin.

Müsgens, F., 2004. Market power in the German wholesale electricity market: an analysis of marginal costs and prices. EWI Working Paper.

Nanduri, V., Das, T.K., 2007. A reinforcement learning model to assess market power under auction-based energy pricing. IEEE Transactions on Power Systems, 85-95.

Newbery, D., 2002. Mitigating market power in electricity networks, Department of Applied Economics. University of Cambridge.

Nicolaisen, J., Petrov, V., Tesfatsion, L., 2001. Market power and efficiency in a computational electricity market with discriminatory double-auction pricing. IEEE Transactions on Evolutionary Computation 5, 504-523.

Rahimiyan, M., Rajabi Mashhadi, H., 2008. Supplier's optimal bidding strategy in electricity pay as bid auction: comparison of the Q-Learning and a modelbased approach. Electric Power Systems Research 78, 165-175.

Stoft, S., 2002. Power System Economics: Designing Markets for Electricity. IEEE/Wiley Press.

Sun, J., Tesfatsion, L., 2007. Dynamic testing of wholesale power market design: an open-source agent-based framework. Computational Economics 30, 291-327.

Sweester, Al., 1999. Measuring a dominant firm's market power in a restructured electricity market, a case study of Colorado. Utilities Policy 7, 243-257.

Sutton, R.S., Barto, A.G., 1998. Reinforcement Learning: An Introduction. MIT Press Cambridge, MA

Tesfatsion, L., 2002. Agent-based computational economics: growing economies from the bottom up. Artificial Life 8, 55-82.

Tesfatsion, L., Judd, K.L., 2006. Handbook of Computational Economics. Agentbased Computational Economics, first ed, vol. 2. Elsevier.

US DOJ/FTC, 1997. 1992 Horizontal Merger Guidelines. Washington, DC, Revised in 1997.

Watkins, C.J.C.H., 1989. Learning from delayed rewards, Ph.D. Thesis. King's College, Cambridge, UK.

Wolak, F.A., 2005. Lessons from international experience with electricity market monitoring. Policy Research Working Paper Series.

Wood, A.J., Wollenberg, B.F., 1996. Power Generation, Operation, and Control. John Wiley \& Sons.

Zarnikau, J., 2005. A review of efforts to restructure Texas' electricity market Energy Policy 33, 15-25. 